\title{
Holograms in Albumins and Optical Properties Recorded in Real Time
}

\author{
Arturo Olivares-Pérez ${ }^{1 *}$, Manuel Jorge Ordóñez-Padilla1, Santa Toxqui-López² \\ ${ }^{1}$ Optics Department, Instituto Nacional de Astrofisica Opticay Electronica, Puebla, Mexico \\ ${ }^{2}$ Facultad de Ingenieria, Benemerita Universidad Autonoma de Puebla, Puebla, Mexico \\ Email: *olivares@inaoep.mx
}

Received 20 March 2015; accepted 12 May 2015; published 15 May 2015

Copyright (C) 2015 by authors and Scientific Research Publishing Inc.

This work is licensed under the Creative Commons Attribution International License (CC BY).

http://creativecommons.org/licenses/by/4.0/

(c) (i) Open Access

\begin{abstract}
Holographic recording analysis was performed on the films that were sensitized with ammonium dichromate with albumin of hen and quail (Gallus gallus and Callipepla cali) as abiopolymeric photosensitive matrix. The samples were exposed to an He-Cd laser, $\lambda=442 \mathrm{~nm}$, at various concentrations, and diffraction efficiencies were measured as a function to the energy, thickness, protein density, aging time, and spatial frequencies. The photosensitivity was measured as a function of storage time, and the gratings were recorded in real time. The photochemical processes involved in the formation of holographic image are described. The results indicate the behavior of colloidal systems based on albumin bird build holographic recording materials.
\end{abstract}

\section{Keywords}

\section{Biopolymer, Proteins, Holograms, Albumins, Diffraction Gratings, Diffraction Devices}

\section{Introduction}

The protein density of the albumin of quail egg is higher than that of hen egg [1] [2]. The albumins were dehydrated in a container with silica gel to form crystal and the density was measured. This process was performed to obtain the percentage of water for each albumin. Photosensitive emulsion (ADPHA) was prepared using holographic recording analysis on films sensitized with ammonium dichromate $\left(\mathrm{NH}_{4}\right)_{2} \mathrm{Cr}_{2} \mathrm{O}_{7}(\mathrm{AD})$ [3]-[5], propylene glycol (P) [6]-[8] with hen albumin (HA). In addition to holographic recording analysis, the photosensitive emulsion (ADPQA) method was produced with quail albumin (QA). Experimental techniques (albumin mixed with $\mathrm{P}$ and $\mathrm{AD}$ ) in the preparation processes were established. The photosensitive emulsions, ADPHA and ADPQA, were used the aqueous AD solution for obtaining the best optimization of high-quality photosensitive

\footnotetext{
${ }^{*}$ Corresponding author.
}

How to cite this paper: Olivares-Pérez, A., Ordóñez-Padilla, M.J. and Toxqui-López, S. (2015) Holograms in Albumins and Optical Properties Recorded in Real Time. Optics and Photonics Journal, 5, 177-192. 
film. The AD solution was prepared to $21 \%$, which corresponded to the saturation limit; when these concentrations were high; the emulsions were crystallized, which were inadequate for holographic recording. In addition, the concentrations with $\mathrm{AD}$ to $1 \%, 5 \%$ and $10 \%$ were prepared for the emulsions; without problems of saturation. We show in all graphic the $\mathrm{AD}$ concentrations at $10 \%$ and $21 \%$, discarding for $1 \%$ and $5 \%$ due to the low diffraction efficiency; it is also discarded the graph with the concentration of $20 \%$ which is very similar to $21 \%$.

Films were prepared with propylene glycol-albumin for producing homogeneous matrixes (emulsions) for obtaining better results [9]. The matrixes were optimized to obtain the best diffraction efficiency (DE) of holographic gratings by studying their behavior as a function of the thickness and recorded [10]-[12]. Experimental studies demonstrate that at an equal amount, the quail albumin contains a larger amount of protein with regard to hen albumin [13] [14]. These mixtures (AD-propylene glycol-albumin) produce weak electrostatic interactions generated by the properties of functional groups of proteins and a combination to facilitate solubility and gel formation [15]-[17]. The films were recorded on an optical setup suitable for hologram recording. The behavior of the emulsion thickness, with DE the optimum energy for high DE for ADPQA gratings and ADPHA at different concentrations were monitored and recorded. The storage time was analyzed before exposing the films (photosensitivity). Aging was observed with a variation in DE with regard to time of the already recorded holographic gratings. The capacity of films in relation to spatial frequencies by module transfer function (MTF) was determined [18]-[20] by varying the angle between the light beams to form gratings with different periods for both matrixes. All experimental results between the two albumins were compared. A peculiarity of these photosensitive films is that they are self-developed. We compared the conventional emulsions of dichromate gelatin (DCG) and PVA + DC, where the gratings were recorded in real time (without developing process). We observed that the albumins had more diffraction efficiency with regard to conventional emulsions. However, when the dichromate gelatin follows a developing process, it outstrips to gratings made with albumins; however, it does not follow the registration process in real time. The gratings made with PVA have the peculiarity that after the baking process, the life time of the gratings is long. It resembles that emulsions based on albumins have certain limitations; however, it is necessary to derive a stabilization process to stop the deterioration of exposed gratings. Albumins are very vulnerable to temperature; therefore, they cannot follow the process of PVA. Furthermore, they are highly hydrophobic and readily dissolve in water. So, it is not possible to make an aqueous developing process as the DCG emulsions.

The results of this study can be applied to teach physical and chemical properties of proteins (biomaterials), the building of diffractive devices and production techniques of photosensitive materials for holography, and to see the behavior of the protein albumin density with diffractive elements. This study also aimed to discover and study new substances with different types of proteins containing in the albumins for the manufacture of volume transmission holograms. Through more research, these substances will compete with the already reported results [21]-[23].

The behavior of the poultry proteins in the formation of holographic gratings and the physicochemical description of the mechanisms were involved in this process, without pretensions to compete with commercial films are also discussed in this paper. Given the high complexity of the protein, structures are still being researched with regard to the stabilization of the images recorded with this matrix.

\section{Experimental Section}

\subsection{Quail and Hen Albumins}

The results of many literatures with regard to hen proteins contained in egg and quail egg [1] [2] [13] [14] are similar to the results obtained experimentally in the laboratory (Table 1). The albumins were dehydrated in a dehydrator of silica gel to form crystals and to measure its density. This process was performed to know the water percentage. The separation technique was applied by decantation (separating water from the protein), producing a higher surface tension of albumin and protein concentration. The experimental results show a dependence on the species of birds; we tested that the quail eggs used in the laboratory showed higher albumin protein density.

The refractive index was measured using an Abbe Refractometer (model Vista C10 ${ }^{\circledR}$, Science lab. USA) with measuring range $1.300-1.700 \mathrm{nD}$. The measurements of albumins were made with a wavelength of $\lambda=587.6$ $\mathrm{nm}$. 
Table 1. Parameters of quail albumins and hen.

\begin{tabular}{ccc}
\hline Parameters & Quail eggs & Hen eggs \\
\hline Albumin liquid (ml) & 20 & 20 \\
Albumin liquid (g) & 20.59 & 20.38 \\
Proteins and trace (g) & 3.007 & 3.26 \\
Albumin dry proteinsand trace (ml) & 2.42 & 2.88 \\
Protein and trace (\%) & 14.6 & 16.12 \\
Water elimination (ml) & 17.583 & 84 \\
Water elimination (\%) & 85.4 & 9.59 \\
Albumin liquid, pH & 9.65 & 1.02 \\
Density (g/ml), 24 ${ }^{\circ} \mathrm{C}$ of albumin liquid & 1.03 & 1.132 \\
Density (g/ml), 24 ${ }^{\circ} \mathrm{C}$ of proteins and trace (dehydrated) & 1.243 & Rank \\
Enviroment parameters & $35-45$ & $20-24$ \\
Relative humidity $(\%)$ & 751 &
\end{tabular}

\subsection{Photosensitive Films}

In the working out of the holographic recording medium, it is important to consider fresh eggs in the preparation of albumin for good photo-oxidation with AD. By magnetic stirring of the albumin, proteins absorbed oxygen at the interface through (air/protein), which generates foam; thus, the denaturation of proteins begins. Adding P to albumin, the foam was reduced, increasing the yield of albumin in preparation of films for holographic recording. For the preparation of each ADPQA film and ADPHA, specific amounts of volume: $20 \mathrm{ml}$ of (QA or HA) + $1.5 \mathrm{ml}$ of $\mathrm{P}+5 \mathrm{ml}$ of $\mathrm{AD}$ at $1 \%, 5 \%, 10 \%, 20 \%$, and $21 \%$, respectively, were placed in a beaker. Each mixture was then stirred well at 30 minutes to get a homogeneous mixture, which was deposited on glass substrates of 5 $\mathrm{cm} \times 5 \mathrm{~cm}$ to form 17 photosensitive films of different thicknesses. The films were dried at room temperature for 24 hours on an average. With the concentration suitable (AD) for the construction of optimal gratings with high $\mathrm{DE}$, these results demonstrate the ability of protein for storage holographic information, and with regard to types of proteins contained in the quail albumin; the ADPQA is more efficient. The expiration date of the egg, to achieve better $\mathrm{DE}$ in holographic gratings was considered.

\subsection{Absorbance}

The absorption spectrum of ADPHA and ADPQA with different concentrations of AD in aqueous presentation shown in Figure 1, was performed with a spectrophotometer (Perkin Elmerk Lambda ${ }^{\circledR}$ 3B UV Visible, Waltham, MA, USA). The photosensitive concentrations at $10 \%$ and $21 \%$ have a high absorption profile in the UV spectral range of $200 \mathrm{~nm}$ to $230 \mathrm{~nm}$, and then rapidly decreased from $230 \mathrm{~nm}$ to $420 \mathrm{~nm}$. After $420 \mathrm{~nm}$, the four curves showed an increase in the absorbance till $525 \mathrm{~nm}$, and after this value, the black curve reduced its absorbance values, similar behavior in $530 \mathrm{~nm}$ for the red and green curves, and in $550 \mathrm{~nm}$ the blue curve.

These films were irradiated by laser $(\lambda=442 \mathrm{~nm})$, with the experimental setup. Significant changes in absorbance profiles of the four samples are shown. When irradiated, samples of $10 \%$ suffer a considerable reduction of absorbance in the UV-visible zone for $200-420 \mathrm{~nm}$; that is, the material reduces its electronic transitions ( $\pi$ orbital). They show a reduction in absorbance for each one of the samples; that is, samples are clearer on exposure. On the other hand, when the samples of $21 \%$ are irradiated at $442 \mathrm{~nm}$, they suffer a considerable change in the absorbance profile, and the quail and hen albumins show relative maximums at $210 \mathrm{~nm}, 270 \mathrm{~nm}$, and $367 \mathrm{~nm}$ UV range; that is, the material displays a behavior of electronic transitions ( $\pi$ orbital). The spectral response in the band range from $410 \mathrm{~nm}$ to $550 \mathrm{~nm}$ suffers a slight clearance by radiation (optical density). The results are shown in Figure 2; significant changes are observed in the UV zone at 200 - $400 \mathrm{~nm}$ absorbance when the samples are irradiated, and also in the visible region there are changes in absorbance amplitude; that is, a slight darkening is observed in $21 \%$ and $10 \%$ of samples. When exposed to laser light, these materials show mixed behavior, and they have a phase and amplitude component. In this way, this material registers its holographic information. The strongest transition with $\pi$ orbitals from the samples to $21 \%$, occurs in the region between $200 \mathrm{~nm}$ 


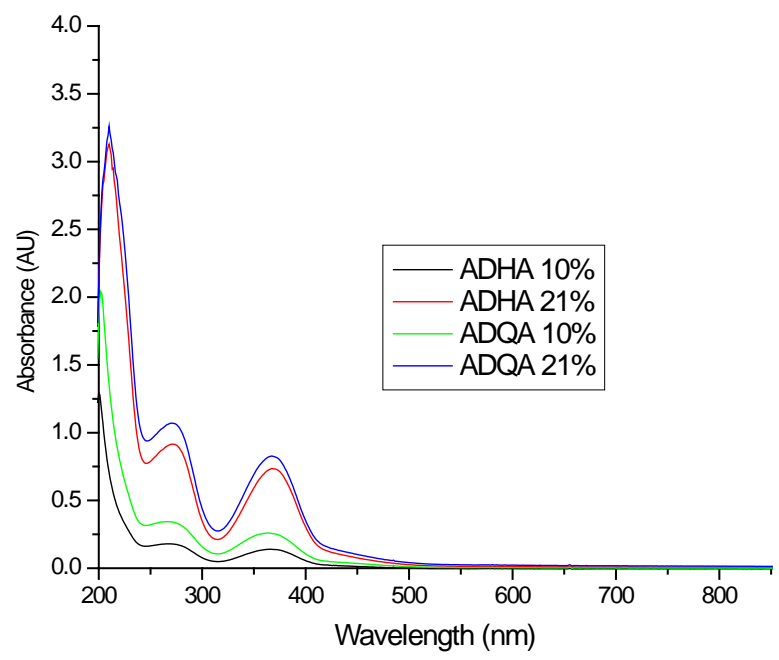

Figure 1. Absorption profile of ADPHA and ADPQA.

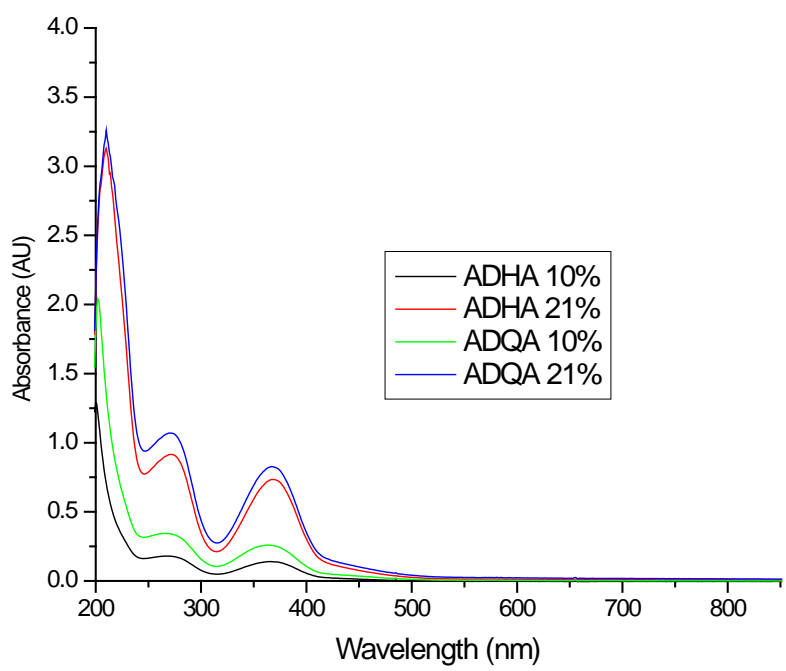

Figure 2. Absorption profile of ADPHA and ADPQA, which were irradiated with a laser, $\lambda=442 \mathrm{~nm}$.

to $250 \mathrm{~nm}$. That is, the modulation is increased in that area.

\section{Results and Discussion}

\subsection{Holographic Gratings}

With ADPHA hen albumin, and ADPQA quail, diffraction gratings were constructed. With an aqueous solution of $\mathrm{AD}$ at $21 \%$ to saturation limits was prepared. The best holographic gratings with ADPQA were reconstructed by using a He-Ne laser, $\lambda=632.8 \mathrm{~nm}$, seen in Figure 3(b). For the measurement of DE to first order, it is the quotient of the sum of intensities of the orders +1 and -1 , with regard to incident beam intensity $\left(I_{i}\right)$ of the form $\eta=I_{ \pm 1} / I_{i}$. Pictures show superior orders with low intensity, which are from diffraction gratings of a low frequency (668 lines $/ \mathrm{mm}$ ) derivatives its amplitude component and phase. The ADPQA matrix shows that diffracted orders slightly have different intensity than the gratings shown in Figure 3(a). The photosensitive films with these albumins initially have a yellowish appearance due to AD. The gratings follow the model for low frequency, for diffraction gratings.

Cross-sections of Figure 3(a) and Figure 3(b) is shown in Figure 4, show a saturation effect due to the limitation of the camera photosensor, for the order -1 and zero. The diffracted orders had no intensity symmetry due 

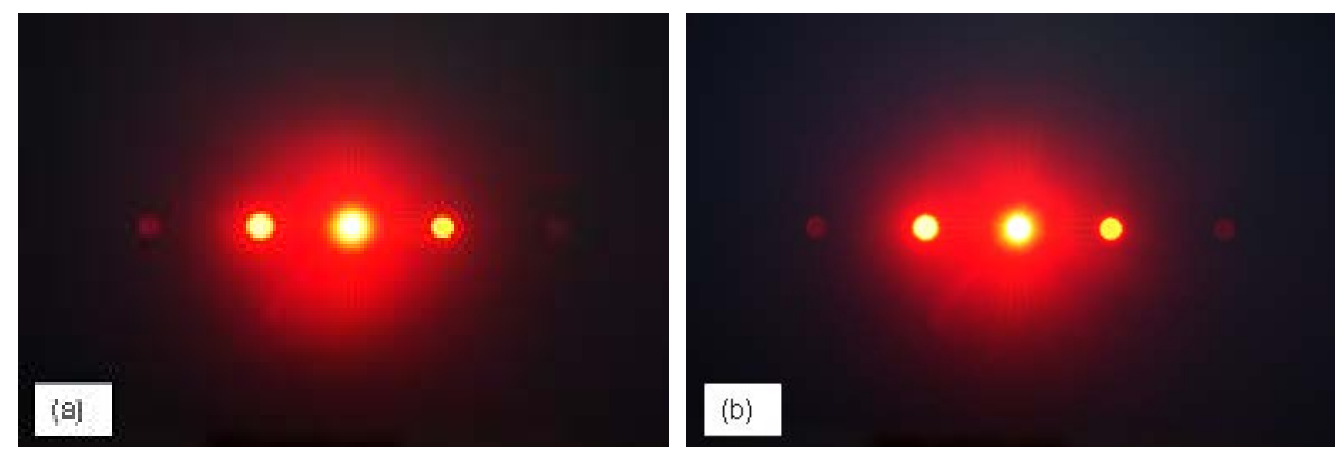

Figure 3. Reconstruction of diffraction pattern of gratings with emulsions: (a) ADPHA, and (b) ADPQA.

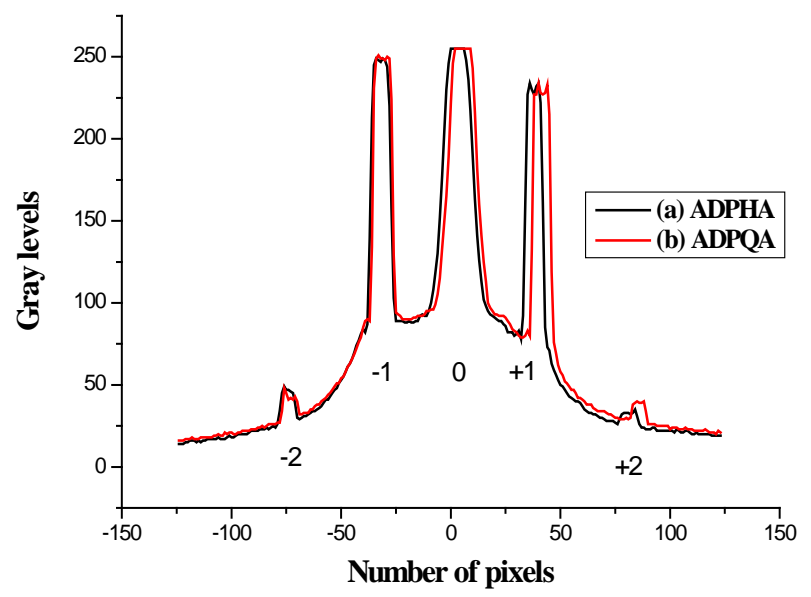

Figure 4. Cross-Section of diffracted intensity pattern of Figure 3(a) ADPHA, Figure 3(b) ADPQA.

to small differences in intensity between the light beams that were overlapped to form the gratings. The noise corresponds to the zero order (halo), and is superimposed on the diffracted orders, due to the low spatial frequency of gratings. When the spatial frequency increases, the diffracted orders do not overlap with the halo.

Figure 4 show interesting behavior, because it is not a typical sinusoidal function, due to overexposed light on material, generates a high modulation function that resembles a square profile, with a significant contribution of phase; thus, the first diffracted orders are very intense. The mixed nature of the photosensitive material, that is, amplitude and phase, is shown with this behavior. This result can be attributed to Mie scattering (halo), because in all the emulsion, large numbers of nuclei of $\mathrm{AD}$ are distributed that are linked to proteins following a spherical symmetry with diameter size in the order of $1 \mu \mathrm{m}$; the calculation was made through the profile of the distribution of noise in the Figure 4 [24] [25].

\subsection{Energy}

Figure 5 indicates the behavior of the DE vs. exposure energy of diffraction gratings built with photosensitive emulsions of ADPHA and ADPQA, with optimal thickness for each one of the matrixes. Exposure with He-Cd laser was measured every 60 seconds. The samples with a concentration of AD $21 \%$ have ascending values of DE until 1250 seconds, after this time, the curves have a decrease in the value of the diffraction efficiency, as evident in the saturation by overexposure of the material. Figure 5 shows the behavior of the emulsions relating to the recorded energy. With an energy of $1100 \mathrm{~mJ} / \mathrm{cm}^{2}$, the ADPQA emulsion with an AD of $21 \%$ and a thickness of $30 \mu \mathrm{m}$ has a DE of $43.3 \%$. With an energy of $1000 \mathrm{~mJ} / \mathrm{cm}^{2}$, the ADPQA film with AD was prepared to $10 \%$, with a thickness of $25 \mu \mathrm{m}$ and an efficiency of $27.6 \%$. For hen albumin, emulsion of ADPHA with AD concentration to $21 \%$, with optimal film thickness of $25 \mu \mathrm{m}$, was applied an energy of $1300 \mathrm{~mJ} / \mathrm{cm}^{2}$, and it presented DE in the order of $36.8 \%$. For the other sample with a thickness of $20 \mu \mathrm{m}$, the ADPHA emulsion, with 


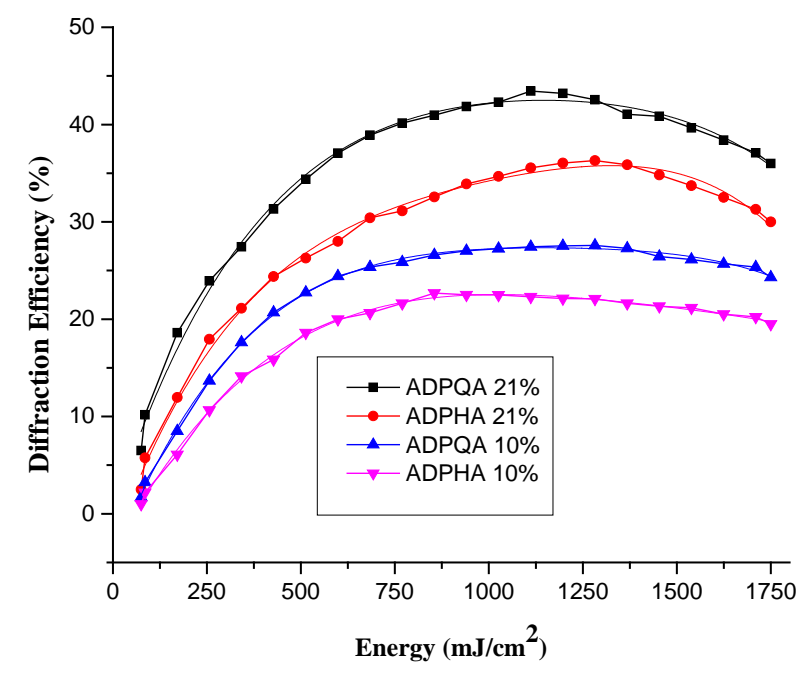

Figure 5. Diffraction efficiencies vs. energy, of holographic gratings; ADPQA andADPHA, at $21 \%$ and $10 \%$ concentration.

dichromate prepared at $10 \%$ with energy of $850 \mathrm{~mJ} / \mathrm{cm}^{2}$ has $22.7 \%$ efficiency. It is remarkable to note that the density difference between albumins ADPQA and ADPHA is associated with DE. The best results obtained with the parameters of concentration and thicknesses were the most optimal, as shown in these graphs. The differences are substantial for both albumins, when the $\mathrm{AD}$ concentration was increased. The proteins contained in the albumin assimilate well the dichromate; these have good capacity of modulation for the formation of holographic gratings. Higher values of $\mathrm{DE}$ are observed with quail albumin due to the higher density of proteins see Table 1. It is evident that the saturation to $10 \%$ is less than the emulsion with $21 \%$; the reduction of diffraction efficiency is less fast, than the curves to $21 \%$.

\subsection{Thicknesses}

The result in Figure 6 shows the changes of DE with regard to thickness of films ADPQA and ADPHA. This was measured with a digital micrometer (Mitutoyo Corporation ${ }^{\circledR}$ Model IP65, Aurora, USA). The thicknesses of films were obtained by pouring different amounts (ml) of photosensitive albumin on an area of the glass substrate. With the measurement at certain points on the substrate thickness without film and with film, the difference of the measures corresponding to the thickness of the emulsion was observed. An average of points on the same substrate to determine the average thickness of the emulsion of the substrate is taken.

An increase in DE of the holographic gratings when the thickness is increased was observed to a maximum value between $15 \mu \mathrm{m}$ to $35 \mu \mathrm{m}$, and then the DE decreased with a further increase in the thickness.

The nature of the proteins of each of the albumins and the variation in wave front propagation through the inside of the films produced a discoloration in the irradiated area, that is, changing the optical density of the material. Exposure time was $1200 \mathrm{~s}$, with an intensity $\left(I_{r}\right)$ on the interference zone of $I_{r}=1.37 \times 10^{-3}$ watts, $\lambda=442$ $\mathrm{nm}$, for each film. With AD prepared to $21 \%$, the grating with hen albumin of $25 \mu \mathrm{m}$ thickness has a DE of $36.8 \%$ and for $90 \mu \mathrm{m}$, the DE was $22 \%$. However, the grating of the quail albumin of $30 \mu \mathrm{m}$ thickness had a DE of $43.3 \%$, and with $90 \mu \mathrm{m}$ it was $27 \%$ with an $\mathrm{AD}$ at $10 \%$, and the thickness of films ADPQA and ADPHA. When increasing the thickness of quail albumin, the DE grows rapidly and shows a maximum plateau greater than $25 \%$ between the thicknesses from $15 \mu \mathrm{m}$ to $35 \mu \mathrm{m}$, then decays rapidly to $45 \mu \mathrm{m}$, and later changes the slope to a linear decay moderate. With hen albumin and increasing the thickness, the DE rises moderately to $20 \mu \mathrm{m}$, and then has a moderate decay linearly. The maximum DE was $27 \%$ with $25 \mu \mathrm{m}$ for ADPQA and a minimum of $9 \%$ with $90 \mu \mathrm{m}$. For ADPHA, it was $23 \%$ with $20 \mu \mathrm{m}$ and a minimum of $7 \%$ with $90 \mu \mathrm{m}$.

Table 2 shows details of diffraction gratings that were prepared with different concentrations of AD, $1 \%, 5 \%$, $10 \%, 20 \%$, and $21 \%$, where the maximum of DE is related to the thickness and density. 


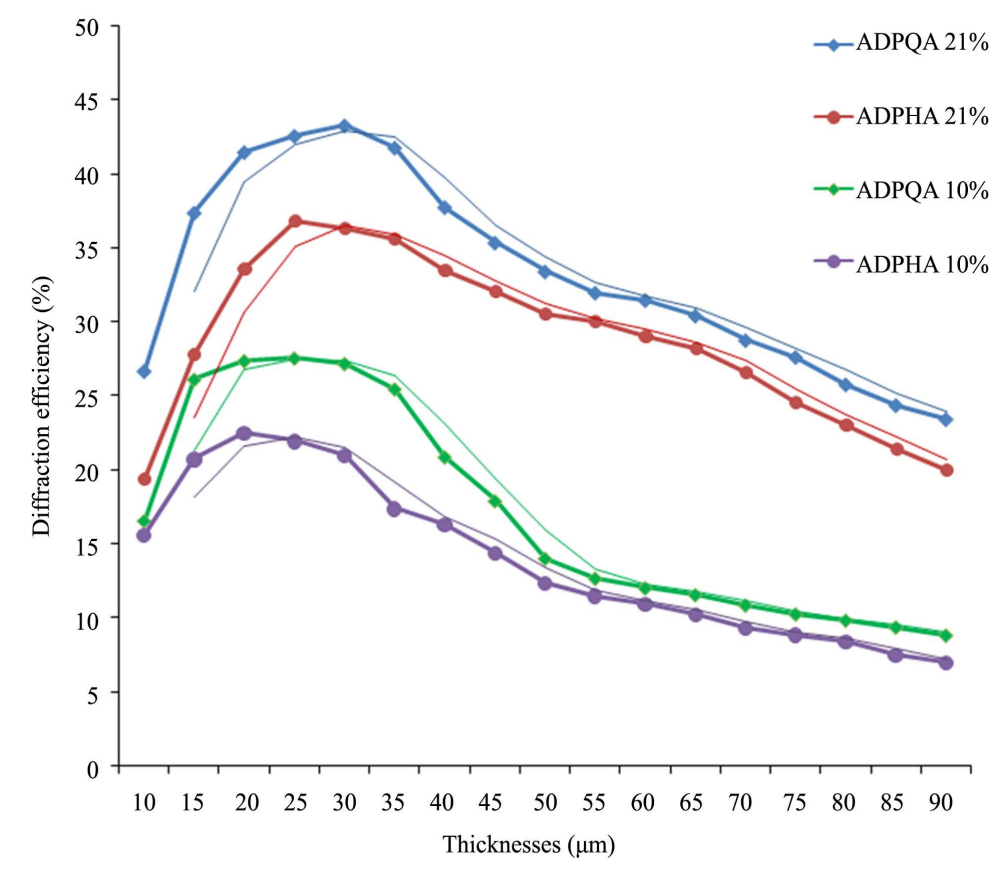

Figure 6. The Diffraction efficiency versus.

Table 2. Parameters from ADPQA and ADPHA.

\begin{tabular}{lcccc}
\hline & AD $(\%)$ & Thickness $(\mu \mathrm{m})$ & Density $(\mathrm{g} / \mathrm{ml})$ & $\eta(\%)$ \\
\hline ADPHA & 1 & 20 & 1.071 & 5 \\
ADPHA & 5 & 20 & 1.095 & 10 \\
ADPHA & 10 & 20 & 1.152 & 22 \\
ADPHA & 20 & 25 & 1.204 & 33 \\
ADPHA & 21 & 25 & 1.215 & 36 \\
ADPQA & 1 & 20 & 1.125 & 6 \\
ADPQA & 5 & 20 & 1.151 & 12 \\
ADPQA & 10 & 25 & 1.219 & 27 \\
ADPQA & 20 & 30 & 1.272 & 40 \\
ADPQA & 21 & 30 & 1.284 & 43 \\
\hline
\end{tabular}

\subsection{Density}

The density of the material determines the relative amount of substances contained in a mixture of several components (mass/volume). These can be obtained from data shown in Table 2. The ADPHA emulsions and ADPQA were prepared for AD concentrations at $1 \%, 5 \%, 10 \%, 20 \%$, and $21 \%$, respectively. The concentration of AD is related to the increase of DE of gratings and the density. The ADPQA emulsion has more density due to the nature of proteins forming quail albumin that is in Figure 7.

\subsection{Refractive Index with Kogelnik's Coupled Wave Theory}

Experimental observations were made to indirectly determine the refractive index of ADPHA and ADPQA, for a dry film, using Kogelnik's coupled wave theory (Equation (1)), for mixed gratings of phase and amplitude [26].

$$
\eta=\left[\operatorname{sen}^{2}\left(\pi n_{1} d / \cos \theta_{0}\right)+\operatorname{senh}^{2}\left(\alpha_{1} d / 2 \cos \theta_{0}\right)\right] \mathrm{e}^{\left(-2 \alpha d / \cos \theta_{0}\right)}
$$


Reconstructing gratings at normal incidence, therefore the angle $\theta_{0}$ is zero, where $n_{1}$ and $\alpha_{1}$ are the amplitudes of the modulation of the refractive index and the absorption constant irradiated, and $\alpha$ is the average absorption. Solving for $\Delta n$ as a function of diffraction efficiency (normalized) Equation (2), and plotting with the variation of diffraction efficiency to obtain Figure 8.

$$
\Delta n=\frac{\cos \left(\theta_{0}\right) \sin ^{-1}\left(\sqrt{\mathrm{e}^{2 \alpha d / \cos \left(\theta_{0}\right)}-\left[\operatorname{senh}\left(\alpha_{1} d / 2 \cos \left(\theta_{0}\right)\right)\right]^{2}}\right)}{\pi d}
$$

where $\eta$ is the diffraction efficiency of gratings recorded in the ADPHA and ADPQA, $\lambda$ is wavelength of the reading, $(632.8 \mathrm{~nm}), d$ is the thickness of the sample $(30 \mu \mathrm{m})$, and $\theta_{0}=0$ is the readout angle incidence on the photomaterial.

Table 3 shows the values of the absorption coefficients $\alpha_{1}$ exposed, and $\alpha$ unexposed, for different concentrations of $\mathrm{AD}$.

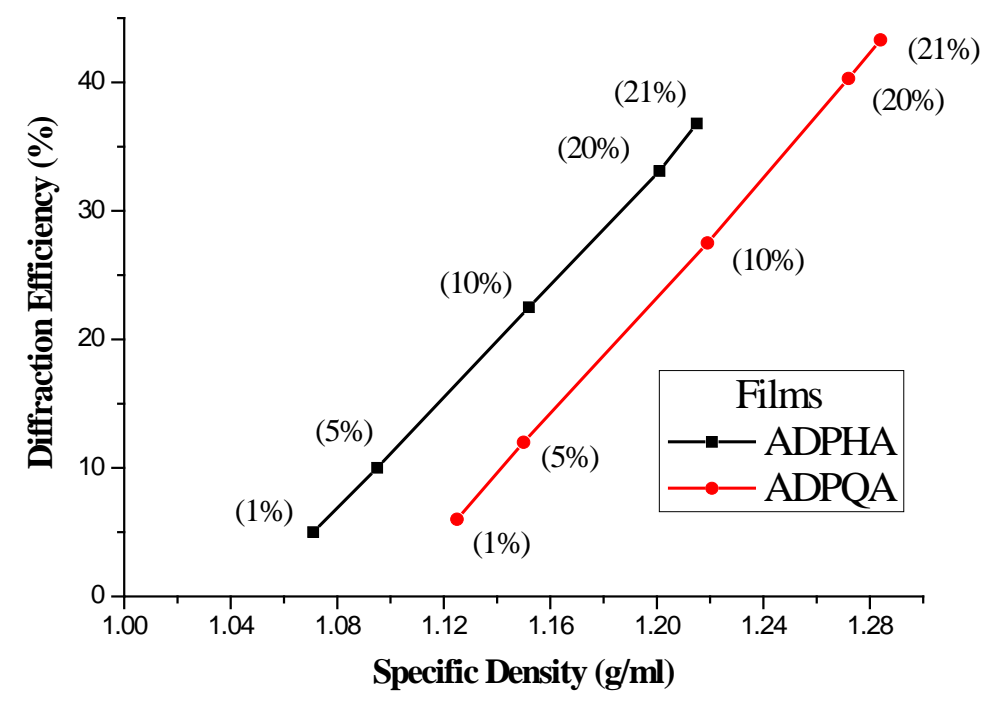

Figure 7. Diffraction efficiency with regard to the density of films.

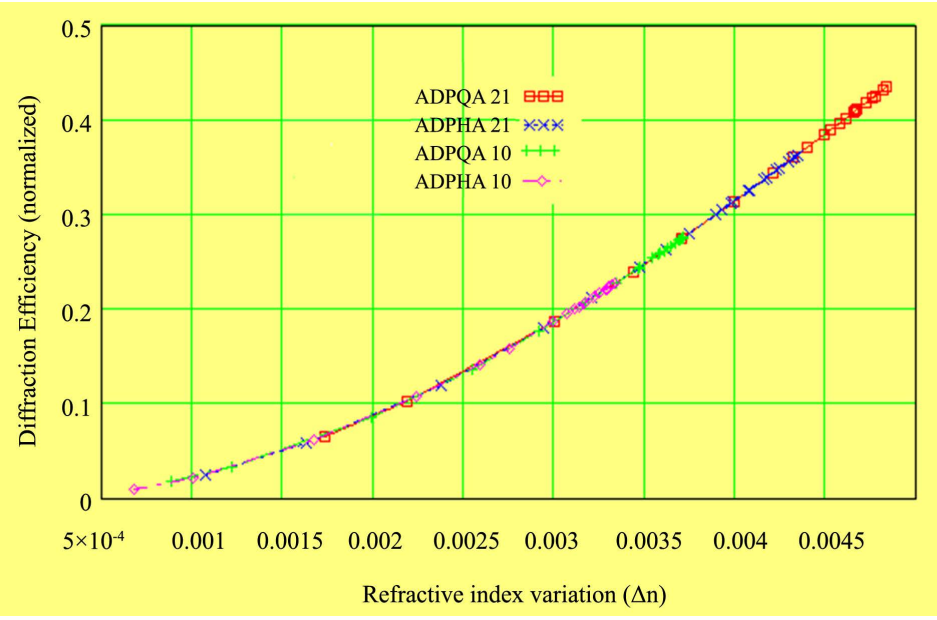

Figure 8. Was built computing different $\Delta n$ for each emulsion and concentration of AD, for the $\mathrm{x}$ and $\mathrm{y}$ axes. The emulsion of ADPQA $21 \%$ has a high density values with $\Delta n$ between 0.0045 and 0.0048 ; for ADPHA $21 \%$, the high density of values of $\Delta n$ is located between 0.0038 and 0.0043 . These are more significant to obtain a high diffraction efficiency in the gratings. 
Table 3. Absorption coefficients of the photosensitive material made with ADPHA and ADPQA at $\lambda=632.8 \mathrm{~nm}$, fordray films with $30 \mu \mathrm{m}$.

\begin{tabular}{ccccc}
\hline & ADPQA 21\% & ADPHA 21\% & ADPQA 10\% & ADPHA 10\% \\
\hline$\alpha$ & 0.0002453 & 0.0001931 & 0.0001223 & 0.000121 \\
$\alpha_{1}$ & 0.0004717 & 0.0004202 & 0.0001912 \\
\hline
\end{tabular}

The refraction index variation $(\Delta n)$ by Kogelnik's theory was obtained from the data of Figure 5, as a function of energy, which is implicitly related to diffraction efficiencies and the optimum specific thicknesses, from emulsions formed with ADPQA and ADPHA.

\subsection{Refractive Index Variation ( $\Delta n)$, by Kogelnik's theory for ADPQA and ADPHA}

Using Equation (2) with the data in Figure 5, we note the following variation behavior $\Delta n$ of the refractive index as a function of energy with a constant thickness of $30 \mu \mathrm{m}$ for each emulsion, with photosensitizers at $10 \%$ and $21 \%$, respectively.

Analyzing the data, we observe that the variation of refractive index $\Delta n$ for holographic gratings ADPHA and ADPQA, with the different concentrations of ammonium dichromate, is not linear. This behavior is interesting, due to the applying of the data of diffraction efficiency of the Figure 5, and the data of Table 4, to obtain the graph of Figure 8. Thus, ADPQA gratings have more diffraction efficiency, with $21 \%$ AD due to more variation of refractive index $\Delta n$. The thickness is an important parameter; Equation (2) shows that the thickness is inversely proportional to the magnitude of changes in the refractive index $\Delta n$. If we consider larger thicknesses, the values of the changes of the refraction index are reduced.

Table 4 shows significant results described in the text, where AD (\%) corresponds to dichromate concentration, $\eta$ is the diffraction deficiency (\%), $T$ is the thickness of the emulsion, and $\Delta n$ indicates the index changes.

\subsection{Photosensitivity vs. Storage Time}

The results in Figure 9 indicate that how the prepared emulsion loses its photo-sensitivity throughout time for different times after storage. The deterioration of photo-sensitivity is due to dehydration and auto-oxidation (darkening) of proteins. A critical reduction of curves DE in recording holographic gratings with emulsions prepared after 96 hours was observed. With a drying of about 24 hours, the photosensitive films show the maximum performance of holographic recording. Regardless of the different concentrations of $\mathrm{AD}$, a strong deterioration of photosensitivity with regard to storage time of films was observed. This behavior was expected, because it is similar to dichromate gelatin, understanding that the gelatin is also a set of proteins.

\subsection{Aging of Gratings}

The holographic gratings showed a change in DE with time. Due to the natural conditions of the environment, the gratings which were recorded showed a darkening over storage time, indicating they still have an oxidation process. The DE reduction (aging) was measured for each hologram till 30 days, after which nonlinear behavior was observed. In all instances, for the optimal gratings, a similar process of deterioration was observed, depending on the DE as shown in Figure 10.

The gratings with a higher DE of $21 \%$ require a faster aging time to reach the minimum values, than the grating with $10 \%$. The oxidation process is responsible for the deterioration of the gratings; with a greater concentration of dichromate, the deterioration is faster. As shown in Figure 10, the gratings with 10\% have a timed life much greater than the gratings with $21 \%$. The almost constant behavior of the diffraction efficiency in gratings with $10 \%$ after 15 days says that the process of oxidation of the emulsion was completed and is stable. Tests were made with gratings at $5 \%$ and $1 \%$ dichromate; the stabilization time is shorter, but diffraction efficiencies are lower, resulting in $12 \%$ and $6 \%$, respectively.

To reduce aging, the gratings need to be stabilized chemically, but we have not yet stabilized high concentrations of dichromate (high efficiency). For low concentrations, it is easy, as the material has a natural stabilization time but a low efficiency.

Table 5 shows the ammonium dichromate with the concentrations of a saturation limit to 21\%; it was unable to stabilize the oxidation process between the proteins of albumen. Even after recording the grating, the process 
Table 4. Refractive index variation $(\Delta n)$, with Kogelnik's theory for ADPQA and ADPHA with a constant thickness.

\begin{tabular}{ccccc}
\hline Samples & $\mathrm{AD}(\%)$ & $\eta(\%)$ & $T(\mu \mathrm{m})$ & $\Delta n$ \\
\hline ADPQA & 21 & 43.3 & 30 & 0.004815 \\
ADPHA & 21 & 36.3 & 30 & 0.004312 \\
ADPQA & 10 & 27.2 & 30 & 0.003691 \\
ADPA & 10 & 21 & 30 & 0.003319 \\
\hline
\end{tabular}

Table 5. Behavior of the gratings, with different concentrations of dichromate and the stabilization time.

\begin{tabular}{|c|c|c|c|c|}
\hline Samples & $\begin{array}{c}\text { Efficiency } \\
\eta \text { (max) }\end{array}$ & $\begin{array}{c}\text { Efficiency } \\
\eta \text { (stable) }\end{array}$ & $\begin{array}{c}\text { Days } \\
\text { stabilization }\end{array}$ & $\begin{array}{l}\text { Life time } \\
\text { (days) }\end{array}$ \\
\hline ADPQA 21\% & $43 \%$ & ---------- & --------- & 42 \\
\hline ADPHA 21\% & $37 \%$ & ---------- & --------- & 40 \\
\hline ADPQA $10 \%$ & $27 \%$ & $12 \%$ & 15 & $>90$ \\
\hline ADPHA 10\% & $22 \%$ & $7 \%$ & 15 & $>90$ \\
\hline ADPQA 5\% & $12 \%$ & $6 \%$ & 6 & $>90$ \\
\hline ADPHA 5\% & $10 \%$ & $5 \%$ & 6 & $>90$ \\
\hline ADPQA 1\% & $6 \%$ & $3 \%$ & 2 & $>90$ \\
\hline ADPHA 1\% & $5 \%$ & $2 \%$ & 2 & $>90$ \\
\hline
\end{tabular}

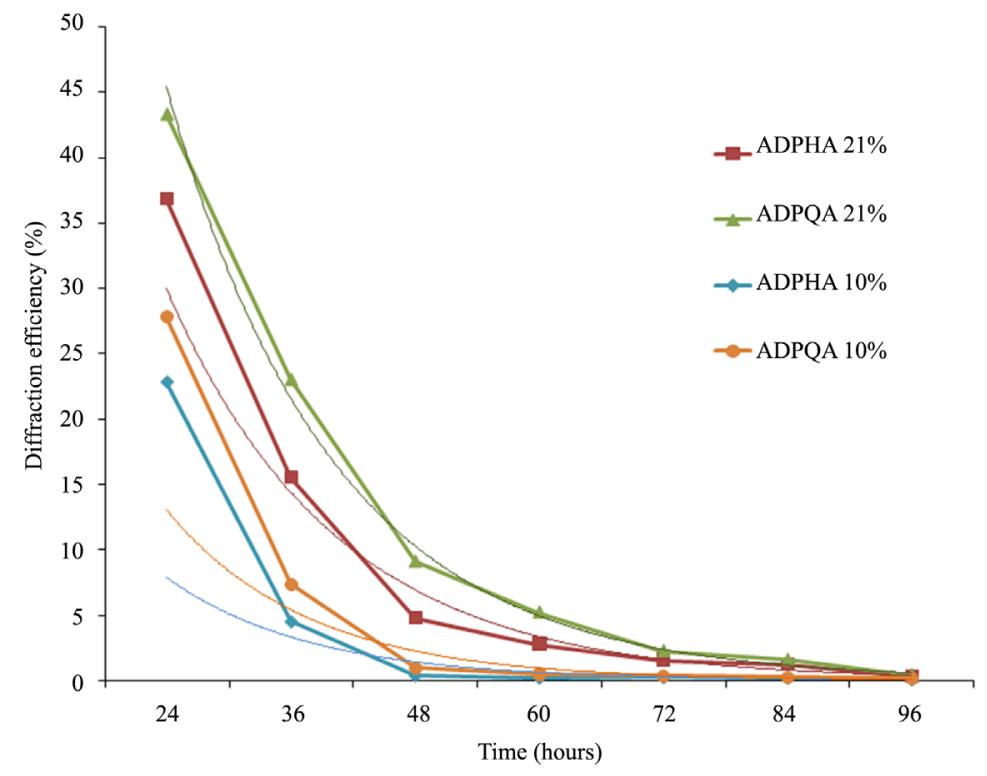

Figure 9. Diffraction efficiency with time storage.

continued without stopping until the grating entirely deteriorated.

\subsection{Spatial Frequency of MTF Analysis}

The modulation transfer function (MTF) is a concept for lenses usually used to determine the response capacity of the lens in a spatial frequency domain, where an object with certain spatial frequencies is mapped as an image. The MTF corresponds to normalize the values that displayed the behavior as spatial frequencies mapped into the image. Similarly, in holography, an analog can be done, when recording an interference pattern, which is composed of spatial frequencies; the photosensitive film records some specific spatial frequencies for each grating (image). The DE parameter was calculated as the ratio of the diffracted beam intensity to the incident intensity that corresponds to normalized values as the MTF. The behavior of DE reduction as a function of the spatial 
frequencies of ADPQA gratings and ADPHA at different AD concentrations is shown in Figure 11. Diffraction gratings with different spatial frequencies were obtained with the experimental setup; the films were recorded at different angles to make holographic gratings with multiple spatial frequencies. With a concentration of AD at $21 \%$, the holographic ADPHA gratings were worked with a thickness of $30 \mu \mathrm{m}$. The reconstruction of grating was performed using a He-Ne laser $\lambda=632.8 \mathrm{~nm}$; the diffracted orders formed an angle of $12.20^{\circ}$, between the +1 order and zero order, which corresponds to the spatial frequency of grating of 668 lines $/ \mathrm{mm}$, with a maximum value of $\mathrm{DE}$ of $36.8 \%$. With this same matrix, the spatial frequency of 1171 lines $/ \mathrm{mm}$ and an angle of $21.74^{\circ}$ corresponds to a minimum value of DE, with only $2 \%$. The ADPQA film was worked to a thickness of $30 \mu \mathrm{m}$ with a spatial frequency of grating of 668 lines $/ \mathrm{mm}$, and the DE was $43.3 \%$; with a spatial frequency of 1171 lines $/ \mathrm{mm}$, the DE was 2.6\%. Experimental results indicate that the DE of ADPQA is higher than ADPHA for the same spatial frequencies.

The behavior of MTF reduces its values according to spatial frequency with a concentration of $\mathrm{AD}$ to $10 \%$, as shown in Figure 11. The holographic grating of ADPQA with a spatial frequency of 668 lines/mm had a maxi-

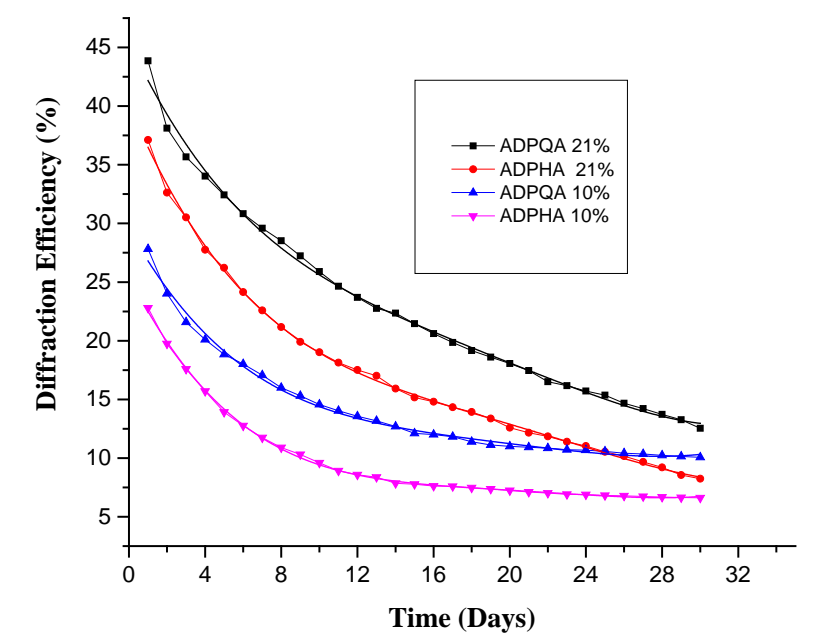

Figure 10. Aging of gratings, diffraction efficiency vs. time (days).

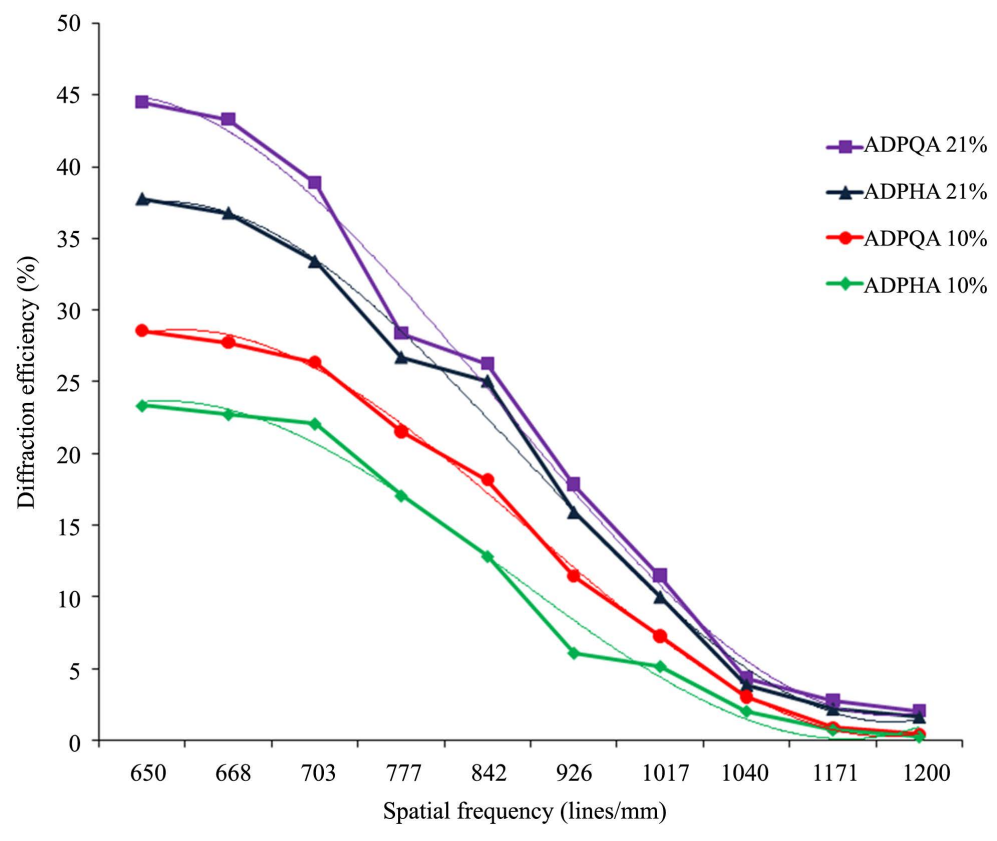

Figure 11. Spatial frequency MTF for holographic grating. 
mum value of DE of $27.8 \%$, and with a spatial frequency of 1171 lines/mm, the DE was $0.9 \%$. Similarly, for ADPHA with a spatial frequency of 668 lines $/ \mathrm{mm}$, the DE was $22.8 \%$, and for the spatial frequency of 1171 lines/mm, the efficiency was $0.8 \%$. The curves of ADPQA film always have a higher DE than do the ADPHA film. For both cases, with different AD concentrations with $21 \%$, and $10 \%$ respectively, we experimentally found that with more protein in albumin, best results are obtained for holographic recording.

The diffraction efficiency curves depend only on the nature of the material, in Section 3.11.1 a physicochemical reaction diagram is described, a possible mechanism that explains how the image is recorded in the material. The physical phenomenon involved in this process would be that the grooves, of the gratings at low frequency, are formed with more energy per area than high-frequency grooves, this energy stimulates the photo crosslinking from material.

\subsection{Microstructure of Gratings}

Microphotographs of holographic gratings constructed (a) ADPHA and (b) ADPQA, both with a concentration of $\mathrm{AD}$ at $21 \%$ and with a groove period of $1.497 \mu \mathrm{m}$ of the gratings, with $\mathrm{DE}$ of $36.8 \%$ and $43.3 \%$, respectively, as shown in Figure 12.

Microphotographs of the grooves in gratings constructed with ADPQA (b), the dark fringes are slightly thinner than in ADPHA (a), allowing to obtain a better quality to reconstruct the diffracted pattern. These images were obtained using an Optical Microscope (Olympus BX51 ${ }^{\circledR}$, Center Valley, PA, USA).

\subsection{Photochemical Processes}

The formation holographic image through of the photochemical processes involved is described as follows: The albumin matrix containing AD produces events where ammonium ions have the effect of accelerating the rate of reduction of $\mathrm{Cr}^{6+}$, [27]. In medium basic, $\mathrm{pH}>9$, it is reduced hexavalent chromium, $\mathrm{Cr}^{6+}$, to pentavalent, $\mathrm{Cr}^{5+}$, and reaches in reduced trivalent, $\mathrm{Cr}^{3+}$. Forming localized links is due to the polarity of sulfides and carboxylic amino, of functional groups of proteins [28]. This photo-structuring is due to macromolecular cross-linking of denatured proteins [29]. The recombination involves macroradical species formation by the transfer of electrons from the electron-donating functional groups of the denatured protein molecules to excited-state chromium species (VI) [28] [30] and implies that the photochemical reactions obscure the matrix and the reduction of Cr (VI) and oxidation of proteins simultaneously; it was generating the modification of the supramolecular structure of biopolymers [31]. The albumin matrices have basic characteristics: The dichromate ions become in chromate, $\left(\mathrm{CrO}_{4}^{2-}\right)$, monomers form. In a fast stage, $\mathrm{Cr}^{6+}$ is photo-reduced to $\mathrm{Cr}^{5+}$ (meta-stable oxochromium ion) [32]. It involves electron transfer of the biopolymer matrix to the metallic cation, giving rise to the formation of an anion-macroradical and to chromium $(\mathrm{V})$, initiating the process of image formation till the reduction of $\mathrm{Cr}^{3+}$ [27]-[34]. Proteins have rather complex chemical structures and photo-products formed along the biopolymeric chains; on the whole, photo-redox processes are different. The photo-stability of the matrixhas been demonstrated experimentally with hologram recording, allowing proposing the dichromated albumin as a good photosensitive biomaterial [34] [35]. There are no published reports of a detailed explanation of chemical reactions

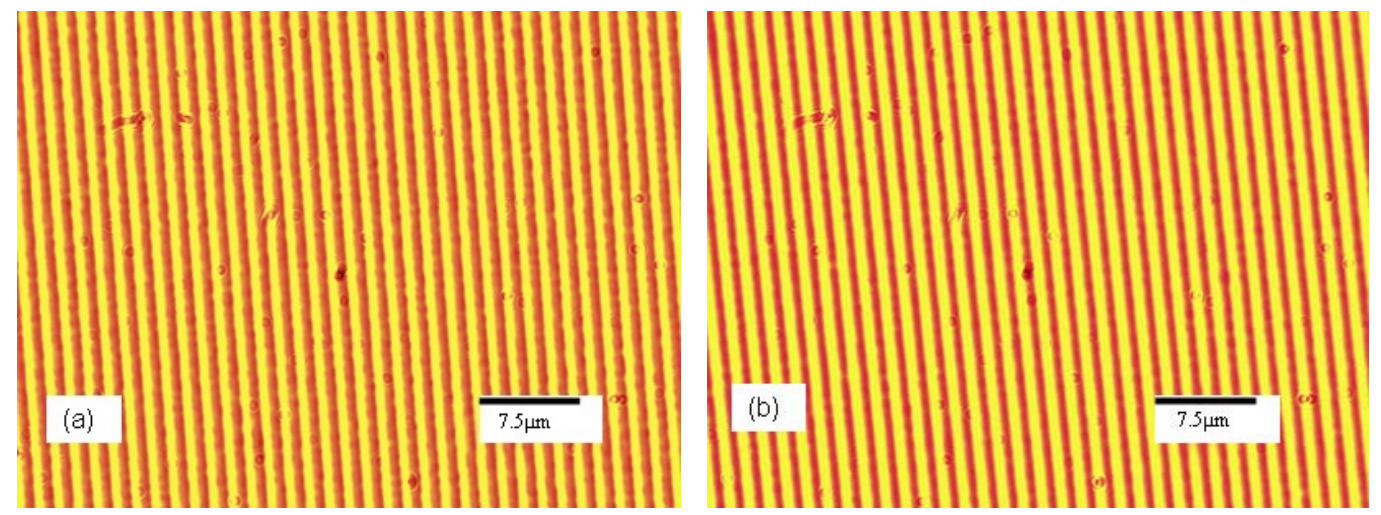

Figure 12. Microphotographs of holographic gratings constructed with ADPHA (a) and ADPQA (b), these were observe with an Optical Microscope. 
that have taken place. The system is complex and multifactorial; thus, it involves several control components. Such factors are moisture, temperature, form of radiation, $\mathrm{pH}$, density, high-molecular weights, a variety of functional groups, and biochemical composition. Describing physical-chemical mechanisms involved in the formation of the holographic grating is not possible at the moment, nor are they clarified satisfactorily in others' manuscripts. The preparation of biopolymeric matrix for the holographic recording is based on references [27][38]. A scheme was generally proposed of the chemical reaction related to the photo-redox process of dichromated albumin. With basic characteristics, the dichromate ion becomes a chromate ion (monomer form), chromium (VI) primary species, Equation (3). The functional groups (carboxylic amino) of proteins behave similar to anionic species, Equation (4). The number of protein molecules in the native state, $\mathrm{xP}_{\mathrm{s}} \mathrm{nAD} \mathrm{D}_{(\mathrm{le})}$, are denatured to $\mathrm{xP}_{\mathrm{s}} \mathrm{dAD}_{(\mathrm{le})}$ by magnetic stirring, Equation (5), passing a state of aggregation, $\left(\mathrm{P}_{\mathrm{s}} \mathrm{d}\right)_{\mathrm{x}} \mathrm{AD}$, that is, gelled (dehydration grade) in 24 hours at ambient conditions, Equation (6). Features are essentially irreversible gel imposed by the type and nature of crosslinks, intra-or intermolecular involved in their formation. In the photo-redox process, the molecules $\left(\mathrm{P}_{5} \mathrm{~d}\right)_{\mathrm{x}}$ chemically combined with $\left(\mathrm{Cr}^{6+} \mathrm{O}_{7}\right)^{2-}$, dichromate ions, in $\mathrm{NH}_{4}{ }^{+}$, ammonium ions, and $\mathrm{OH}^{-}$, hydroxyl ions, continuously absorb photons, $\lambda=442 \mathrm{~nm}$, that are generated in excitation state, and exhibit a conformational transition for recording. A number of molecules produced modified anionic proteins $\left(\mathrm{yP}_{\mathrm{s}} \mathrm{m}:{ }^{-}\right)$, more $\left(\mathrm{Cr}^{6+} \mathrm{O}_{4}\right)^{2-}$, chromate ions, Equation (7). The change in $\mathrm{pH}$ alters the distribution ofpoints in cationic, anionic, and nonionic polar protein molecules. Thus, the alkaline $\mathrm{pH}$ multiplies the anionic species, ( $\mathrm{yP}_{\mathrm{s}} \mathrm{m:} \mathrm{-}^{-}$). In a second stage, photo-reduction of $\mathrm{Cr}^{6+}$ to $\mathrm{Cr}^{5+}$ (meta-stable species) starts the process of image recording and it can be explained with the formation of anion-macroradical and $\mathrm{Cr}^{5+}$, Equation (8). The final stage involves photo-reduction of $\mathrm{Cr}^{5+}$ to $\mathrm{Cr}^{3+}$ (stable species). Protein molecules were modified in the form of anionmacroradical that interacts with $\mathrm{Cr}^{5+}$ ions and is reduced to $\mathrm{Cr}^{3+}$ by electron transfer. Lastly, the macroradicalquelated with $\mathrm{Cr}^{3+}$ was obtained, where the photo-crosslinking of recorded image ends, Equation (9), [32]-[38].

\section{Diagram Chemical Reactions}

1) Preparation of biopolymer matrix (albumin) for holographic recording

Dissociation of ammonium dichromate in basic medium:

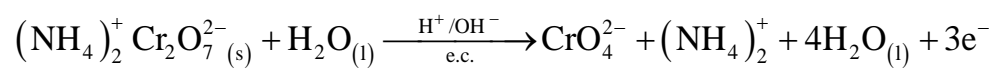

The dichromate ion becomes the chromate ion (monomer form), primary chromium (VI) species, in basic medium, $\mathrm{pH}>9$.

The proteins behave as anionic species of functional groups (carboxylic amino):

$$
\mathrm{H}_{3} \mathrm{~N}^{+} \text {-CRH-COO:- } \underset{\mathrm{H}^{+}}{\stackrel{\mathrm{OH}^{-}}{\rightleftarrows}} \mathrm{H}_{2} \underset{\text { (ion at high pH) }}{\mathrm{N}-\mathrm{CRH} \text { ) }}
$$

Protein denaturation

$$
\mathrm{xP}_{\mathrm{s}} \mathrm{nAD}_{(l e)} \frac{\begin{array}{c}
\mathrm{T}=22^{\circ} \mathrm{C} \\
\text { magnetic stiring }
\end{array}}{\text { propylene glycol }} \longrightarrow \mathrm{xP}_{\mathrm{s}} \mathrm{dAD}_{(l e)}
$$

$\mathrm{X}=$ number of protein molecules $\left(\mathrm{P}_{\mathrm{s}}\right) ; \mathrm{n}=$ native state; $\mathrm{d}=$ denatured state; $\mathrm{AD}=$ ammonium dichromate; $\mathrm{C}=$ ammonium chromate; le = liquid emulsion; e.c. $=$ environmental conditions; $\mathrm{l}=$ liquid; gel $=$ gel. Protein aggregation, start crosslinking process

$$
\mathrm{xP}_{\mathrm{s}} \mathrm{dAD}_{(l e)} \underset{24 \text { hours/lec. }}{\stackrel{\text { dehydation }}{\longrightarrow}}\left(\mathrm{P}_{\mathrm{s}} \mathrm{d}\right)_{(\mathrm{gel})} \mathrm{AD}
$$

2) Image recording, photo-crosslinking in the film

Photo-redox process.

First stage. Electronic excitation and conformational transition in basic medium in the process of holographic recording: First stage.

$$
\left(\mathrm{P}_{\mathrm{s}} \mathrm{d}\right)_{\mathrm{x}}+\mathrm{Cr}^{6+}(\mathrm{AD}) \underset{\text { (excitation state) }}{\stackrel{\mathrm{h} v=442 \mathrm{~nm}}{\mathrm{NH}_{4}^{+} / \mathrm{OH}^{-}}}\left[\mathrm{yP}_{\mathrm{s}} \mathrm{m}^{-}+\mathrm{Cr}^{6+}(\mathrm{C})\right]^{*}
$$

$\mathrm{yP}_{\mathrm{s}} \mathrm{m}:=$ number anionic modified protein molecules; ${ }^{*}=$ excited state.

Second stage. Photo-reduction of $\mathrm{Cr}^{6+}$ to $\mathrm{Cr}^{5+}$ (meta-stable species). Starts fast process of image formation. 


$$
\left[\mathrm{yP}_{\mathrm{s}} \mathrm{m}^{-}+\mathrm{Cr}^{6+}(\mathrm{C})\right]^{*} \frac{\mathrm{h} v=442 \mathrm{~nm}}{\text { photo-crosslinking }} \underset{\text { (anion-macroradical-oxochromium) }}{\left[\mathrm{yP}_{\mathrm{s}} \mathrm{m}^{-}---\mathrm{Cr}^{5+}\right]}
$$

Third stage. Photo-reduction of $\mathrm{Cr}^{5+}$ to $\mathrm{Cr}^{3+}$ (stable species). Slow process where the photo-crosslinking ends. It was generated macroradically and quelated with $\mathrm{Cr}^{3+}$; stable finish image.

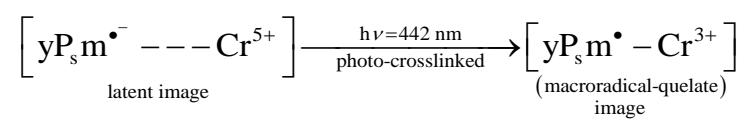

\section{Conclusion}

The results indicate the behavior of colloidal systems based on albumin bird, to build holographic recording materials. All gratings show a self-developed property, that is, you do not need an aqueous chemical treatment to extend or develop the image. We observed that the albumins had a higher diffraction efficiency with regard to conventional emulsions with dichromate gelatin. However, when the dichromate gelatin follows a developing process, it outstrips gratings made with albumins, but it does not follow the registration process in real time. Albumin is formed by several proteins. In this research, it can be observed that the albumin protein density is an important factor to obtain better quality in the recording medium. The diffraction efficiencies were good when the density was high. In this work, we used hen albumin and quail, proving that quail albumin was the best to make holograms. Another important point corresponds to thickness map vs. DE, for the ADPHA emulsions and ADPQA for concentrations of $10 \%$ and $21 \%$, respectively. All curves have the same growth and decay profile, following the same shape of its relative maxima, skewed to the left. Refractive index variation $(\Delta n)$, with Kogelnik's theory for ADPQA and ADPHA with a constant thickness is represented, where nonlinear behavior of the variation of refractive index as a function of the diffraction efficiency is shown. The curves in the UV-visible absorbance of the ADPQA emulsions and ADPHA, have significant results; the absorbance changes when the samples are irradiated, $\lambda=442 \mathrm{~nm}$. The material displays a behavior of electronic transitions of the structures with conjugated $\pi$ orbitals which are present in the biopolymers. To describe, in detail the physical-chemical mechanisms involved in the formation of the image are a huge task of high complexity owing to the structures of proteins. For this reason, the chemical reactions were described in general (Section 3.11.1). Factors such as humidity and temperature variation over time should be controlled to avoid affecting the hologram.

\section{Acknowledgements}

Thanks are due to The Instituto Nacional de Astrofisica Optica y Electronica (INAOE) for the infrastructure and economic support received.

\section{Author Contributions}

Arturo Olivares-Pérez directs, coordinates, and funds the entire investigation. This work is a part of the experimental results obtained in the thesis project of M. Jorge Ordóñez-Padilla, a PhD student. Santa Toxqui-López collaborated on the investigation of the behavior of diffraction gratings.

\section{References}

[1] Closa, S.J., Marchesich, C., Cabrera, M. and Morales, J.C. (1999) Composición de Huevos de Gallina y Codorniz, Archivos Latinoamericanos de Nutrición, Órgano Oficial de la Sociedad Latinoamericana de Nutrición. Venezuela, 49, 181-185.

[2] Stadelman, W.J. and Cotterill, O.J. (1995) Egg Science and Technology. 4th Edition, The Haworth Press, NY, 115119.

[3] Dalgaard, G.A.P., Hazell, A.C. and Hazell, R.G. (1974) The Crystal Structure of Ammonium Dichromate, $\left(\mathrm{NH}_{4}\right)_{2} \mathrm{Cr}_{2} \mathrm{O}_{7}$. Acta Chemica Scandinavica, 28, 541-545. http://dx.doi.org/10.3891/acta.chem.scand.28a-0541

[4] Kalyashova, Z.N., Michailova, A.G., Pavlov, A.P., Rykov, V.S. and Cuba, B.S. (1991) High Sensitive Layers of Dichromated Gelatin for Hologram Recording by Continuous Wave and Pulsed Laser Radiation. Three-Dimensional Holography: Science, Culture, Education. Proceedings of SPIE, Kiev, 189-194.

[5] Tharayil, G., Kutty, G. and Hua-Kuang, L. (1987) Simplified Dichromated Gelatin Holograms Recording Process. Ap- 
plied Optics, 26, 372-376. http://dx.doi.org/10.1364/AO.26.000372

[6] Ruddick, J.A. (1972) Toxicology, Metabolism, and Biochemistry of 1,2-Propanediol. Toxicology and Applied Pharmacology, 21, 102-111. http://dx.doi.org/10.1016/0041-008X(72)90032-4

[7] Gaunt, I.F., Carpanini, F.M., Grasso, P. and Lansdown, A.B. (1972) Long-Term Toxicity of Propylene Glycol in Rats. Food and Cosmetics Toxicology, 10, 151-162. http://dx.doi.org/10.1016/S0015-6264(72)80193-7

[8] Barr, M. and Linwood, F. (1957) A Study of the Inhibitory Concentrations of Glycerin Sorbitol and Propylene GlycolSorbitol Combinations on the Growth of Microorganisms. Journal of American Pharmaceutical Association, 4, 217218. http://dx.doi.org/10.1002/jps.3030460404

[9] Pérez Salinas, P., Mejias Brizuela, N.Y., Olivares Perez, A., Grande Grande, A., Páez Trujillo, G., Hernandez Garay, M.P. and Fuentes Tapia, I. (2008) Hologramwitheggalbumin. In Practical Holography XXII: Materials and Applications. Proceedings of SPIE, San Jose, 1-8.

[10] Alfernes, R. and Case, S.K. (1976) Coupling in Doubly Exposed Thinck Holographic Gratins. Journal of the Optical Society of America, 65, 730-739. http://dx.doi.org/10.1364/JOSA.65.000730

[11] Magnusson, R. and Gaylord, T.K. (1976) Use of Dynamic Theory to Describe Experimental Results from Volume Holography. Journal of Applied Physics, 47, 190-199. http://dx.doi.org/10.1063/1.322343

[12] Magnusson, R. and Gaylord, T.K. (1977) Analysis of Multiware Diffraction of Thick Gratings. Journal of the Optical Society of America, 67, 1165-1170. http://dx.doi.org/10.1364/JOSA.67.001165

[13] ĐukićStojčić, M., Milošević, N., Perić, L., Jajić, I. and Tolimir, N. (2012) Egg Quality of Japanese Quail in Serbia. Biotechnology in Animal Husbandry, 28, 425-431. www.polj.uns.ac.rs

[14] Genchev, A. (2012) Quality and Compositition of Japanese Quail Eggs (Coturnix Japonica). Trakia Journal of Sciences, 10, 91-101. http://www.uni-sz.bg

[15] Badui, S. (2006) Proteínas. Química de los Alimentos. 4th Edition, Pearson Educación, México, 119-236. https://books.google.com.mx/books?isbn=9702606705

[16] Kinsella, J.E., Damodaran, S. and German, J.B. (1985) V-Physicochemical and Functional Properties of Oil-Seed Proteins with Emphasis on Soy Proteins. New Protein Foods; Seed Storage Proteins. Academic Press. London, 107-179. http://dx.doi.org/10.1016/B978-0-12-054805-7.50012-9

[17] Fligner, K.L. and Mangino, M.E. (1991) Relationship of Composition to Protein Functionality. Interactions of Food Proteins, ACS Symp. Series. American Chemical Society, Washington DC, 1-12. http://dx.doi.org/10.1021/bk-1991-0454.ch001

[18] O’Neill, F.T., Lawrence, J. and Sheridan, J.T. (2001) Thickness Variation of Self-Processing Acrylamide-Based Photopolymer and Reflection Holography. Optical Engineering, 40, 533-539.

[19] Olivares-Pérez, A., Mejias-Brizuela, N.Y., Grande-Grande, A. and Fuentes-Tapia, I. (2012) Corn Syrup Holograms. Optik, 123, 447-450. http://trove.nla.gov.au/version/176478213

[20] Ordóñez-Padilla, M.J., Olivares-Perez, A. and Berriel-Valdos, L.R. (2013) Spatial Frequency Study of Holograms with Albumins Material. Proceedings of SPIE in Practical Holography XXVII: Materials and Applications, San Francisco, 1 March 2013, 2-7. http://dx.doi.org/10.1117/12.2002418

[21] Miniewicz, A., Kochalska, A., Mysliwiec, J., Samoc, A., Samoc, M. and Grote, J.G. (2007) Deoxyribonucleic AcidBased Photochromic Material for Fast Dynamic Holography. Applied Physics Letters, 91, Article ID: 041118. http://dx.doi.org/10.1063/1.2760169

[22] Czaplicki, R., Krupka, O., Essaïdi, Z., El-Ghayoury, A., Kajzar, F., Grote, J.G. and Sahraoui, B. (2007) Grating Inscription in Picosecond Regime in Thin Films of Functionalized DNA. Optics Express, 15, 15268-15273. http://dx.doi.org/10.1364/OE.15.015268

[23] Sahraoui, B., Pranaitis, M., Gindre, D., Niziol, J. and Kažukauskas, V. (2011) Opportunities of Deoxyribonucleic Acid Complexes Composites for Nonlinear Optical Applications. Journal of Applied Physics, 110, Article ID: 083117. http://dx.doi.org/10.1063/1.3655985

[24] Mie, G. (1908) Beiträge zur Optik trüber Medien, speziell kolloidaler Metallősungen. Annalen der Phyeik, 25, 377445. http://dx.doi.org/10.1002/andp.19083300302

[25] Yushanov, S., Jeffrey S.C., and Kyle, C.K. (2013) Mie Scattering of Electromagnetic Waves. Proceedings of the COMSOL Conference, Boston.

[26] Kogelnik, H. (1969) Coupled Wave Theory for Thick Hologram Gratings. The Bell System Technical Journal, 48, 2909-2947. http://dx.doi.org/10.1002/j.1538-7305.1969.tb01198.x

[27] Chenthamarakshan, C.R. and Rajeshwar, K. (2000) Heterogeneous Photocatalytic Reduction of Cr(VI) in UV-Irradiated Titania Suspensions: Effect of Protons, Ammonium Ions, and Other Interfacial Aspects. Langmuir, 16, 2715-2721. http://dx.doi.org/10.1021/la9911483 
[28] Samui, A.B. (2008) Holographic Recording Medium. Recent Patents on Materials Science, 1, 74-94. http://dx.doi.org/10.2174/1874464810801010074

[29] Maloletov, S.M. and Sherstyuk, V.P. (1988) Photoinduced Structure Transformations in Dichromate-Impregnated Denatured Collagen. Teoreticheskayai Eksperimental'naya Khimiya, 24, 247-251. http://dx.doi.org/10.1007\%2FBF00531207

[30] Wang, K., Zhu, J., Tang, J., Guo, L. and Li, Y. (1998) Experimental Research on the Mechanism of Image Formation of Dichromated-Gelatin Holograms. Proceedings of SPIE Holographic Materials IV, 42, 3294. http://tdl.libra.titech.ac.jp/journaldocs/.../ZR00000005712

[31] Sherstyuk, V.P. and Dilung, I.I. (1982) Holographic Recording Media Based on Photochemical Reactions in Dichromated Gelatin. Fundamental Principles of Optical Memory in Media, 13, 34-38.

[32] Bolte, M., Israëli, Y., Djouani, F., Rivaton, A., Frezet, L. and Lessard, R.A. (2005) Hologram Formation Reconsidered in Dichromated Polyvinylalcohol: Polymer Cross-Linking around Chromium (V). Proceedings of SPIE Materials and Applications, Bellingham, 195-204. http://holoforum.org/data/doc/Lessard-PVA dichromate.pdf

[33] Lin, W.Y., Wei, C. and Rajeshwar, K. (1993) Photocatalytic Reduction and Immobilization of Hexavalent Chromium at Titanium Dioxide in Aqueous Basic Media. Journal of the Electrochemical Society, 140, 2477-2482. http://dx.doi.org/10.1149/1.2220847

[34] Israëli, Y., Frezet, L. and Rivaton, A. (2008) Photochemical Processes Involved in a Biopolymer Doped by Chromium (VI) during Hologram Recording. Journal of Macromolecular Science, Part A: Pure and Applied Chemistry, 45, 10371046. https://www.hal.inserm.fr/ICC/hal-00399468 http://dx.doi.org/10.1080/10601320802457840

[35] Chang, B.J. and Leonard, C.D. (1979) Dichromated Gelatin for the Fabrication of Holographic Optical Elements. Applied Optics, 18, 2407-2417. http://dx.doi.org/10.1364/AO.18.002407

[36] Sjolinder, S. (1981) Dichromated Gelatin and the Mechanism of Hologram Formation. Photographic Science and Engineering, 25, 112-118.

[37] Lafond, C., Pizzocaro, C., Lessard, R.A. and Bolte, M. (2000) Primary Photochemical Process in Films of Dichromated Gelatin: A Quantitative Aproach. Optical Engineering, 39, 610-615. http://dx.doi.org/10.1117/1.602405

[38] Boltem, M., Agarwal, G., Pizzocaro, C., Lafond, C. and Lessard, R.A. (2000) Investigation of the Primary Photochemical Process in Chromium Doped Polymeric Material: Interactivity with Holography. Proceedings of SPIE Applications of Photonic Technology, 6671-6668. 